\title{
Ensino Superior no Brasil: cenário, avanços e contradições
}

\author{
Higher Education in Brazil: Scenario, advancements and \\ contradictions
}

\author{
Alexandre de Paula Franco'
}

\section{Resumo}

Este trabalho apresenta um breve conjunto de reflexões que apontam elementos constituintes da educação superior no Brasil nas últimas duas décadas, considerando principalmente o contexto da organização e estrutura do ensino superior no país, apreciando suas mudanças históricas, a identificação do perfil dos alunos ingressantes nesta etapa da educação e a relação com o panorama da educação básica. A proposta é realizar e possibilitar uma visão panorâmica sobre os avanços e os desafios que estão colocados diante da sociedade, quando se trata de ensino superior no Brasil.

Palavras Chaves: Ensino Superior; Qualidade educacional; Democratização; Perfil discente.

\begin{abstract}
This work presents a brief set of reflections which point out forming elements that have been part of Higher Education in Brazil in the last two decades, considering mainly the context of the organization and structure of College Education in this country, showing its historical changes, the identification of the profile of students who are starting out in this new phase of their education and the relationship of all this with the panorama of Basic Education. The goal is to make possible and real a panoramic vision over the advancements and the challenges that are present when it comes to College Education in Brazil

Key-Words: Higher Education; Educational quality; Democratization; Profile of the student body.
\end{abstract}

1'Doutorando no Programa de Pós-Graduação da Faculdade de Educação da Universidade de São Paulo, Mestre em Educação pela FEUSP, Coordenador do curso de Pedagogia do Centro Universitário Salesiano - unidade São Paulo, Professor das disciplinas de Didática e Coordenação do Trabalho na Escola na mesma instituição e Supervisor de Ensino Titular de Cargo Efetivo da Rede Estadual de São Paulo. 


\section{Contexto da Educação Superior no Brasil: alguns dados}

Dados recentes sobre a educação superior no Brasil indicam que vivemos num momento histórico em que temos que lidar com a dualidade nesta etapa educacional: de um lado o grande investimento financeiro nesta fase da educação, fato que não pode ser considerado um problema e de outro, a expansão ainda que pouco expressiva e democratizada do ensino superior.

Certamente, temos a considerar que o ensino superior no Brasil iniciou sua organização mais sistemática a partir de 1934 com a fundação da Universidade de São Paulo. Evento este, que representa uma condição de história recente no cenário educacional. Contudo, não podemos deixar de registrar que o pós-guerra colocou o Brasil numa condição de país que mais expandiu seu sistema de educação, não apenas do nível básico, mas também da educação superior.

MARTINs (2000) afirma que desde o final da década passada, o crescimento da educação superior no Brasil, numa média de $7 \%$ ao ano, produziu uma diversificação da forma de atendimento aos ingressantes, sobretudo na graduação. Contudo, o autor alerta sobre o que se vê desde então, isto é, uma situação de hierarquização institucional sem necessariamente o aprimoramento na relação entre o projeto pedagógico das instituições e as reais necessidades dos jovens e do mercado.

Este processo de expansão foi acompanhado pela ampliação de vagas, mudanças no perfil da população atendida e, conseqüentemente, de construção de alternativas metodológicas e organizativas desta etapa educacional no país, e a definição de sua inserção no mercado, em que se pese a agressiva influência política entre as décadas de 1960 e 1970 até o início dos anos 1980, quando a maioria das instituições de ensino superior seria originada do setor privado.

Os dados apresentados pelo Censo do MEC em 2005 demonstram a expansão das matrículas de acordo com natureza institucional no país. Vejamos uma amostragem:

Expansão das matrículas por modalidade de instituição
(2005)

\begin{tabular}{|c|c|c|c|c|c|}
\hline Ano & $\begin{array}{c}\text { Setor } \\
\text { Público } \\
\text { - vagas }\end{array}$ & $\begin{array}{c}\text { Setor } \\
\text { Público } \\
-\%\end{array}$ & $\begin{array}{c}\text { Setor } \\
\text { Privado } \\
\text { - vagas }\end{array}$ & $\begin{array}{c}\text { Setor } \\
\text { Privado } \\
-\%\end{array}$ & Total \\
\hline 1933 & 18.986 & 56,3 & 14.737 & 43,7 & 33.723 \\
\hline 1945 & 21.307 & 51,6 & 19.969 & 48,4 & 41.275 \\
\hline 1965 & 182.696 & 56,2 & 142.386 & 43,8 & 325.082 \\
\hline 1985 & 556.680 & 40,7 & 810.929 & 59,3 & 1.367 .609 \\
\hline 2004 & 1.178 .328 & 28,3 & 2.985 .405 & 71,1 & 4.163 .733 \\
\hline \multicolumn{5}{|c|}{ Fonte: MEC - Censo INEP 2005. } \\
\hline \multicolumn{6}{|c|}{}
\end{tabular}

Se por um lado, nos deparamos com um crescimento expressivo do atendimento pelas universidades, por outro, este aumento de ingressantes não foi acompanhado pelo fortalecimento do trabalho de muitas instituições. Segundo Moura Castro (2003) apenas dez universidades no país têm de fato um envolvimento considerável em pesquisa. A grande maioria possui alguma atividade desta modalidade embora, muitas vezes frágil e isolada, enquanto que muitas, com um trabalho mais fraco, sobretudo neste aspecto, não têm nenhum vínculo com a pesquisa. O pesquisador ainda alerta que se de alguma forma, existem muitos aspectos a serem revistos nos investimentos em pesquisas, principalmente quanto ao pagamento de pessoal e na efetivação desta atividade acadêmica, não se pode negar que a pós-graduação tem se mostrado como um dos setores mais eficazes da educação brasileira, principalmente no tocante às instituições públicas, que além de pesquisadores, tem ofertado professores para atuarem na docência de cursos de graduação.

O cumprimento das finalidades do ensino superior, baseando-se na prioridade para o ensino, extensão e pesquisa, prevista inclusive no artigo 43, da lei 9394/96, justifica a necessidade de se definir um campo de organização e alternativas de oferecimento e desenvolvimento diversificadas, consistentes e que contemplem tanto os elementos da ciência, como os componentes do ensino.

Evidentemente, o mérito em expandir o ensino superior no país como um instrumento de democratização da educação é algo louvável, principalmente quando reconhecidamente articulado com políticas afirmativas concretas como o Programa Universidade para Todos 
- PROUNI, do governo federal, que até 2003 seria responsável pela inclusão de cerca de 200 mil estudantes. Entretanto, há de se acautelar quanto aos riscos de um possível crescimento desordenado no setor privado, que envia milhares de pedidos de abertura de cursos ao MEC, acirrando a concorrência, multiplicando os cursos, causando o fracionamento de recursos que deveriam ser destinados aos cursos já existentes nestas instituições e por conseqüência, provocando não raramente resultados qualitativos muito aquém do desejável nestas escolas, especialmente a partir da década de 1990, como tem insistentemente alertado os dados levantados pelo INEP - Instituto Nacional de Estudos Pedagógicos.

O levantamento estatístico do INEP sobre a educação superior no Brasil, realizado em 2006, demonstra a agressiva expansão das dependências privadas no oferecimento de cursos superiores em todo o Brasil, como podemos ver:

Tabela 1. Número de instituições de Educação Superior, por organização acadêmica e categoria (2006)

\begin{tabular}{|c|c|c|c|c|c|c|c|c|}
\hline \multirow{3}{*}{\multicolumn{3}{|c|}{$\begin{array}{l}\text { Unidade da } \\
\text { Federação/ } \\
\text { Categoria } \\
\text { Administrativa }\end{array}$}} & \multicolumn{6}{|c|}{ Instituições } \\
\hline & & & \multirow{2}{*}{ 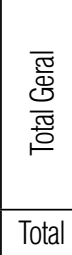 } & \multirow[t]{2}{*}{ 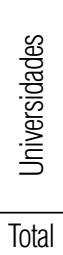 } & \multirow{2}{*}{ 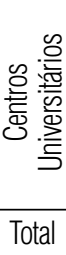 } & 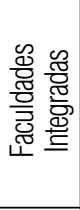 & 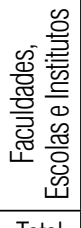 & \multirow[t]{2}{*}{ 惫 } \\
\hline & & & & & & Total & Total & \\
\hline \multirow{8}{*}{ 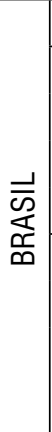 } & & & 2.270 & 178 & 119 & 116 & 1.649 & 208 \\
\hline & \multirow{4}{*}{$\frac{\text { 음 }}{\frac{0}{2}}$} & Total & 248 & 92 & 4 & 4 & 82 & 66 \\
\hline & & Federal & 105 & 53 & - & - & 5 & 47 \\
\hline & & Estadual & 83 & 34 & - & - & 30 & 19 \\
\hline & & Municipal & 60 & 5 & 4 & 4 & 47 & - \\
\hline & \multirow{3}{*}{ 宽 } & Total & 2.022 & 86 & 115 & 112 & 1.567 & 142 \\
\hline & & Particular & 1.583 & 24 & 63 & 92 & 1.268 & 136 \\
\hline & & $\begin{array}{c}\text { Comun/ } \\
\text { Confes/ } \\
\text { Filant }\end{array}$ & 439 & 62 & 52 & 20 & 299 & 6 \\
\hline
\end{tabular}

Fonte: Dados do Levantamento INEP/2006

É muito provável que, medidas de racionalização de recursos destinados aos investimentos sociais que marcam as últimas décadas, tanto no plano federal, como estadual, tenham impactado o desenvolvimento de políticas educacionais efetivamente amplas, contínuas e eficazes. Por efeito, situações como a insuficiência de investimento na educação média e superior, é algo a ser equacionado para tornar mais eficazes os mecanismos de entrada do aluno egresso, sobretudo da rede pública nas escolas superiores, principalmente as que sejam públicas.

Como exemplo da desigualdade de investimento e custos educacionais, o Brasil gasta dez vezes mais no ensino superior do que no ensino médio. Enquanto que nos Estados Unidos o gasto é 2,5 vezes maior e na França é praticamente igual para as mesmas etapas. De alguma forma, estes dados indicam que há incorreções na aplicação de recursos na educação superior, não que necessariamente existam excessos, mas que devam ser vinculados com objetivos, metas e resultados e, sobretudo, aponta para a urgência de ampliação dos investimos na educação básica. Destacamos que é fundamental democratizar a expansão do ensino superior para se poder acenar com melhor continuidade do processo formativo da população brasileira, como em outros países, e para que tal proposição se concretize o papel do Estado em ampliar recursos é primordial, dado que se trata de investimento social justo e esperado.

Schwartzman (2006) quando se refere aos gastos com ensino superior adverte que ampliar o investimento no ensino básico não significa reduzir o que se aplica nesse nível, mas sim ampliar o patamar do PIB de cerca de 4,3\% para 7 a $8 \%$, de modo a se aumentar recursos para a educação básica, que atualmente carece de $3,5 \%$ da cota investida. Contudo, adverte que o aumento de recursos precisa estar aliado a mudança do padrão de gestão das escolas, para uma perspectiva mais democrática e participativa, e se definir padrões de regulação também para o ensino superior.

Quando tratamos do contexto do ensino superior no Brasil, principalmente, a partir da década de 1990, levando em conta as manifestações do MEC, através de disposições legais mais regulamentadoras ou pela utilização de expedientes de agilização, visto o grande número de escolas superiores no país, notamos que houve uma ampliação da autonomia para as instituições na organização de seu projeto pedagógico e seu plano de desenvolvimento institucional.

Como conseqüência desta autonomia institucional, e do aumento das unidades de 
ensino, é fundamental que os profissionais que atuam nestas escolas superiores estejam também nutridos do compromisso da pesquisa, da competência para o ensino e da consciência da função social da educação superior, o que pressupõe ampla discussão com os diversos segmentos da academia, e implantação de mecanismos de regulação do desenvolvimento institucional, da produção acadêmica e dos seus resultados.

Está posto o papel insubstituível do Estado em garantir o cumprimento de padrões mínimos aceitáveis de qualidade, articulando o oferecimento de cursos compatibilizando-os às necessidades reais e demandas sociais, inclusive dos menos favorecidos, seja pelo não acesso, seja pelos benefícios diretos da produção acadêmica. Daí a importância do poder público atuar não exclusivamente em ações de racionalização de recursos, mas de fomento de iniciativas de valorização de profissionais da educação, políticas para ensino superior, e da qualidade na educação básica como via de acesso às escolas superiores.

A realidade brasileira demonstra que 0 acelerado processo de expansão de instituições e cursos favorece o aumento incontrolável de professores que se vinculam exclusivamente às instituições de ensino superior para a docência baseada em horas, gerando o efeito direto na fragilização do fomento à pesquisa em escolas superiores que limitam sua atuação a uma forma de escolarização, sem nem mesmo existir em muitos casos a extensão. Deacordo com os dados do INEP, na avaliação do vínculo profissional dos docentes nas escolas superiores, isolandose a situação existente nas universidades, nos demais segmentos de atendimento à condição para o desenvolvimento da pesquisa ou extensão verifica-se algo extremamente limitado:

Tabela 2. Número Total de Funções Docentes (Em

Exercício e Afastados) em 30/6/2006, por Organização Acadêmica e Regime de Trabalho

\begin{tabular}{|c|c|c|c|c|c|c|c|c|c|c|}
\hline \multirow{3}{*}{\multicolumn{3}{|c|}{$\begin{array}{l} \\
\text { Unidade da Federação/ } \\
\text { Categoria Administrativa }\end{array}$}} & \multicolumn{8}{|c|}{$\overline{B R A S I L}$} \\
\hline & & & & \multicolumn{4}{|c|}{ Pública } & \multicolumn{3}{|c|}{ Privada } \\
\hline & & & & & & & & & & Comun/ \\
\hline \multirow{4}{*}{\multicolumn{2}{|c|}{ 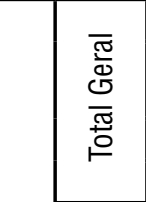 }} & Total & 316.882 & 106.999 & 58.078 & 41.007 & 7.914 & 209.883 & 118.739 & 91.144 \\
\hline & & $\begin{array}{c}\text { Tempo } \\
\text { Integral }\end{array}$ & 113.848 & 80.094 & 48.580 & 30.013 & 1.501 & 33.754 & 16.214 & 17.540 \\
\hline & & TempoParcial & 64.913 & 16.964 & 7.482 & 8.091 & 1.391 & 47.949 & 23.919 & 24.030 \\
\hline & & Horista & 138.121 & 9.941 & 2.016 & 2.903 & 5.022 & 128.180 & 78.606 & 49.574 \\
\hline \multirow{4}{*}{\multicolumn{2}{|c|}{ 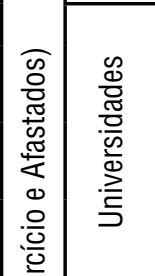 }} & Total & 168.481 & 94.204 & 52.881 & 37.482 & 3.841 & 74.277 & 17.792 & 56.485 \\
\hline & & $\begin{array}{c}\text { Tempo } \\
\text { Integral }\end{array}$ & 91.992 & 73.498 & 44.077 & 28.348 & 1.073 & 18.494 & 5.358 & 13.136 \\
\hline & & $\begin{array}{l}\text { Tempo } \\
\text { Parcial } \\
\end{array}$ & 37.020 & 14.812 & 7.034 & 7.042 & 736 & 22.208 & 5.150 & 17.058 \\
\hline & & Horista & 39.469 & 5.894 & 1.770 & 2.092 & 2.032 & 33.575 & 7.284 & 26.291 \\
\hline \multirow{8}{*}{ 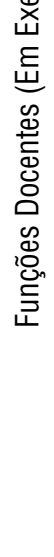 } & \multirow{4}{*}{ 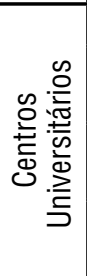 } & Total & 36.024 & 558 & - & - & 558 & 35.466 & 19.283 & 16.183 \\
\hline & & $\begin{array}{l}\text { Tempo } \\
\text { Integral }\end{array}$ & 6.951 & 108 & - & - & 108 & 6.843 & 3.815 & 3.028 \\
\hline & & $\begin{array}{l}\text { Tempo } \\
\text { Parcial } \\
\end{array}$ & & & - & - & 428 & 20.649 & 11.053 & 9.596 \\
\hline & & Horista & 21.077 & 428 & - & - & 428 & 20.649 & 11.053 & 9.596 \\
\hline & \multirow{4}{*}{ 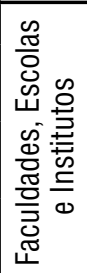 } & Total & 88.230 & 6.068 & 523 & 2.657 & 2.888 & 82.162 & 66.207 & 15.955 \\
\hline & & $\begin{array}{l}\text { Tempo } \\
\text { Integral }\end{array}$ & 9.422 & 2.271 & 424 & 1.527 & 320 & 7.151 & 5.921 & 1.230 \\
\hline & & $\begin{array}{l}\text { Tempo } \\
\text { Parcial }\end{array}$ & 17.332 & 1.757 & 99 & 1.025 & 633 & 15.575 & 12.548 & 3.027 \\
\hline & & Horista & 61.476 & 2.040 & - & 105 & 1.935 & 59.436 & 47.738 & 11.698 \\
\hline
\end{tabular}

Fonte: Dados do Levantamento INEP/2006 
Oportunamente, Krasilchik (2008) destaca que as tensões da educação superior são muitas, principalmente, no campo da discussão sobre produtividade, onde há uma desvalorização da docência para profissionais do ensino superior em favor da pesquisa, como se estas atividades devessem ser colocadas numa situação dicotômica dentro das escolas superiores e não com mecanismos de equilíbrio.

Não basta que tenhamos escolas superiores com recursos disponíveis, ou planos de melhoria ambiciosos. É fundamental o aprimoramento dos recursos humanos envolvidos em todo o processo. A partir dos dados do INEP, divulgados em 2003 acerca das notas obtidas pelas escolas de ensino superior, percebemos que é inadiável o investimento em processos de formação de quadros profissionais que favoreçam a melhoria dos resultados e rendimento dos alunos e cursos, em especial das instituições privadas. Vejamos:

\section{Tabela 3. Desempenho dos tipos de instituições por} conceitos no ENC - 2003

\begin{tabular}{|c|c|c|c|}
\hline Instituições & A e B & C & D e E \\
\hline Federais & 52,5 & 30,2 & 17,3 \\
\hline Estaduais & 34,4 & 32,0 & 33,6 \\
\hline Privadas & 19,3 & 49,8 & 30,9 \\
\hline Municipais & 19,0 & 40,7 & 40,3 \\
\hline
\end{tabular}

As características do ensino superior apresentadas neste trabalho demonstram que a heterogeneidade dos estudantes que ingressam na educação superior, a diversidade regional brasileira e os vários perfis institucionais que se detectam ao avaliar determinados segmentos de escolas, advogam em favor da existência de políticas de equidade, que possibilitem por um lado, ampliar o número de vagas possíveis para o atendimento de alunos nas universidades públicas e por outro, o fomento de programas que contribuam para o financiamento ou o subsídio público do Estado para o acesso de estudantes em escolas privadas. Em ambos os casos, alicerçados por mecanismos de acompanhamento e de regulação do desenvolvimento e qualidade, embora esta segunda alternativa não seja, a nosso ver, a alternativa mais adequada, aconselhável e ideal, do ponto de vista da aplicação de recursos públicos.
Retomamos ainda, que a educação superior não pode prescindir de uma nova e permanente formação de seus profissionais, sobretudo os docentes, tendo em vista que o movimento da desprofissionalização das carreiras tem provocado o encontro de uma nova identidade dos cursos superiores e suas escolas. Muitas carreiras têm se mostrado cada vez mais abertas para diversos cursos, como é o caso da informática, comunicação, mídias; assim, é fundamental que os cursos estejam suficientemente providos de criatividade e flexibilidade curricular e também metodológica.

Ainda acerca das mudanças necessárias para a mudança educacional, Schwartzman (2006) aponta que a melhoria da qualidade da educação básica, democratização da educação superior, adequação da gestão dos recursos financeiros e o alcance da equidade de oportunidades serão mais efetivos à medida que os profissionais da educação estiverem mais comprometidos, havendo salários dignos, relação de cooperação com os gestores educacionais e envolvidos com atividades acadêmicas e intelectuais.

Os dados do INEP indicam que nas últimas duas décadas em muitas regiões do Brasil, o crescimento dos cursos superiores ultrapassou o percentual de $20 \%$ em decorrência da multiplicação desmedida, em muitos casos, de escolas superiores privadas:

Tabela 4. Cursos presenciais por organização acadêmica nas dependências

\begin{tabular}{|c|c|c|c|c|c|}
\hline \multicolumn{6}{|c|}{$\begin{array}{l}\text { Cursos de Graduação Presenciais por organização } \\
\text { acadêmica }\end{array}$} \\
\hline \multirow{2}{*}{\multicolumn{3}{|c|}{$\begin{array}{l}\text { Unidade da Federação/ } \\
\text { Categoria Administrativa }\end{array}$}} & \multirow{2}{*}{\multicolumn{3}{|c|}{$\begin{array}{c}\text { Número de Cursos de } \\
\text { Graduação Presenciais } \\
\text { Total Geral }\end{array}$}} \\
\hline & & & & & \\
\hline & & & Total & Capital & Interior \\
\hline \multirow{8}{*}{ 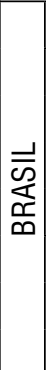 } & & & 22.101 & 7.560 & 14.541 \\
\hline & \multirow{4}{*}{ 氶 } & Total & 6.549 & 1.793 & 4.756 \\
\hline & & Federal & 2.785 & 1.337 & 1.448 \\
\hline & & Estadual & 3.188 & 444 & 2.744 \\
\hline & & Municipal & 576 & 12 & 564 \\
\hline & \multirow{3}{*}{ 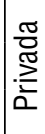 } & Total & 15.552 & 5.767 & 9.785 \\
\hline & & Particular & 9.079 & 3.817 & 5.262 \\
\hline & & Comun/Confes/Fila & 6.473 & 1.950 & 4.523 \\
\hline
\end{tabular}
Fonte: Dados do Levantamento INEP/2006

Como já afirmara Moura Castro (2003) à exceção de poucos cursos como o Direito ou a Medicina, o fato de o crescimento econômico 
nacional estar por volta dos 3\% e o de ampliação e expansão de alguns cursos superiores chegarem a $20 \%$ geraria, inequivocamente, certa saturação em alguns campos. Tal circunstância implica na existência de cursos mais flexíveis e menos especificistas, capazes de contribuírem para o desenvolvimento de competências mais gerais, e das áreas do conhecimento e trabalho, favorecendo o ingresso em campos de trabalho que não sejam tão restritos, além de contribuir para o desenvolvimento da pesquisa e a valorização da extensão a qual não pode ser confundida com a prestação de serviços. Não se trata, pois, da desagregação de cursos ou faculdades, mas sim de uma abordagem mais interdisciplinar, tanto do ponto de vista dos conteúdos conceituais, quanto dos procedimentais e metodológicos.

Está colocado um desafio sem precedentes para os docentes do ensino superior, diante do desafio de garantir uma formação acadêmica substancial baseada na intelectualidade e na perspectiva investigativa, e concomitantemente repensar a organização dos cursos e as possíveis formas de melhoria do impacto dos egressos da educação superior na sociedade.

\section{Perfil do aluno da Educação Superior: indícios da educação básica e reflexos do cotidiano dos estudantes}

Anteriormente, apresentados alguns dados que sugerem a acelerada expansão do ensino superior durante as últimas décadas e, principalmente, nos últimos 20 anos. O fato é que esta expansão, não obstante ao aumento dos campi isolados, é resultado do aumento expressivo de matrículas que chegou a cerca de $140 \%$ entre os anos de 1997 e 2006 . Porém, no último ano, o crescimento medido nas matrículas foi de 5\%, ainda menor que dos anos do início da década, nos quais já em declínio chegava aos $15 \%$. Os índices demonstram que a demanda reprimida no ensino médio, durante décadas, fora de alguma maneira atendida pelas escolas superiores, especialmente as de natureza privada.
O fenômeno do crescimento do ensino superior no período supracitado se deu em muito pela ampliação dos concluintes do ensino médio em todo Brasil. Assim, o processo de democratização e aumento das taxas líquidas das escolas médias impactou fortemente o número de ingressantes na educação superior. Reconhecidamente, a situação até então inusitada, gerou uma circunstância na qual o ensino público não conseguiu oferecer vagas suficientes para toda esta demanda, ficando então a cargo dos serviços privados o atendimento destes alunos egressos da educação média, como constatamos pelos índices de crescimento a seguir, coletados pelo INEP:

Tabela 5. Evolução da transição ensino médio para ensino superior

\begin{tabular}{|c|c|c|c|}
\hline Ano & Concluintes EM & Ingressantes ES & Variação \\
\hline 1980 & 541.000 & 356.667 & 65,93 \\
\hline 1991 & 659.000 & 426.558 & 64,73 \\
\hline 1997 & 1.266 .000 & 527.959 & 41,70 \\
\hline 2002 & 1.855 .419 & 1.036 .690 & 55,87 \\
\hline
\end{tabular}

Fonte: INEP (2005)

No entanto, vale ressaltar que não apenas os egressos do ensino médio têm incrementado os números de ingressantes naeducação superior. No caso do Brasil, são cerca de 25 milhões de jovens entre 18 e 24 aos, ou seja, em idade de educação superior que ainda não tiveram a oportunidade de realizá-la, mesmo já tendo concluído há anos ou sem mesmo ter alcançado a escolarização média. Este cenário aponta para uma provável permanência da expansão quantitativa da educação superior e, simultaneamente, para a relevância de investimentos maciços na escola básica de modo que os egressos possam ao concluir, continuar seu percurso.

As escolas de ensino superior não podem ser concebidas pelos profissionais da educação básica apenas como uma forma de ascensão profissional, ou como única possibilidade de formação imediatamente para a totalidade de seus alunos. Estas podem também representar grandes referências de parceria, colaboração e melhoria do funcionamento da educação básica, principalmente pelo viés da extensão e da pesquisa. Além disso, iniciativas de autêntica colaboração entre instituições 
públicas de ensino básico e superior, têm se mostrado como experiências altamente positivas, e gerado resultados significativos tanto para a identidade da educação superior, para a melhoria da educação básica e para o reconhecimento dos alunos das escolas públicas. Exemplos emblemáticos e de referência a serem citados são os Programas INCLUSP e PASUSP², desenvolvidos pela Universidade de São Paulo, com as escolas médias públicas de São Paulo.

Considerando mais estritamente o perfil pedagógico dos alunos que ingressam no ensino superior, os dados do INEP (2006), demonstram que o desempenho dos alunos egressos do ensino médio carece de desempenho plenamente satisfatório no que se refere às expectativas de aprendizagem para esta etapa. Certamente, não cabe defender a criação de mecanismos de freio do ingresso em escolas superiores, com a finalidade exclusivamente de seleção de elitização da educação superior. No entanto, diante dos resultados mais recentes, a educação básica tem se mostrado deficitária e a etapa seguinte muitas vezes precisa desempenhar a função compensatória.

Os dados apresentados pelo Instituto Nacional de Estudos e Pesquisas Educacionais Anísio Teixeira foram colhidos a partir da realização do Exame Nacional do Ensino Médio (ENEM) 2006 que contou com 3.742.146 inscritos e 2.783.001 participantes. Destes participantes, 1.243 .486 eram concluintes do ensino médio em 2006, 1.402 .509 eram estudantes egressos da escola média, 98.572 estudantes que só concluiriam o curso após 2006 e 38.434 não forneceram a informação de conclusão do ensino médio. Vejamos os dados do INEP, apresentados na tabela 6 do levantamento do ensino médio em 2006:

Tabela 6. Desempenho médio no ENEM - Parte Objetiva

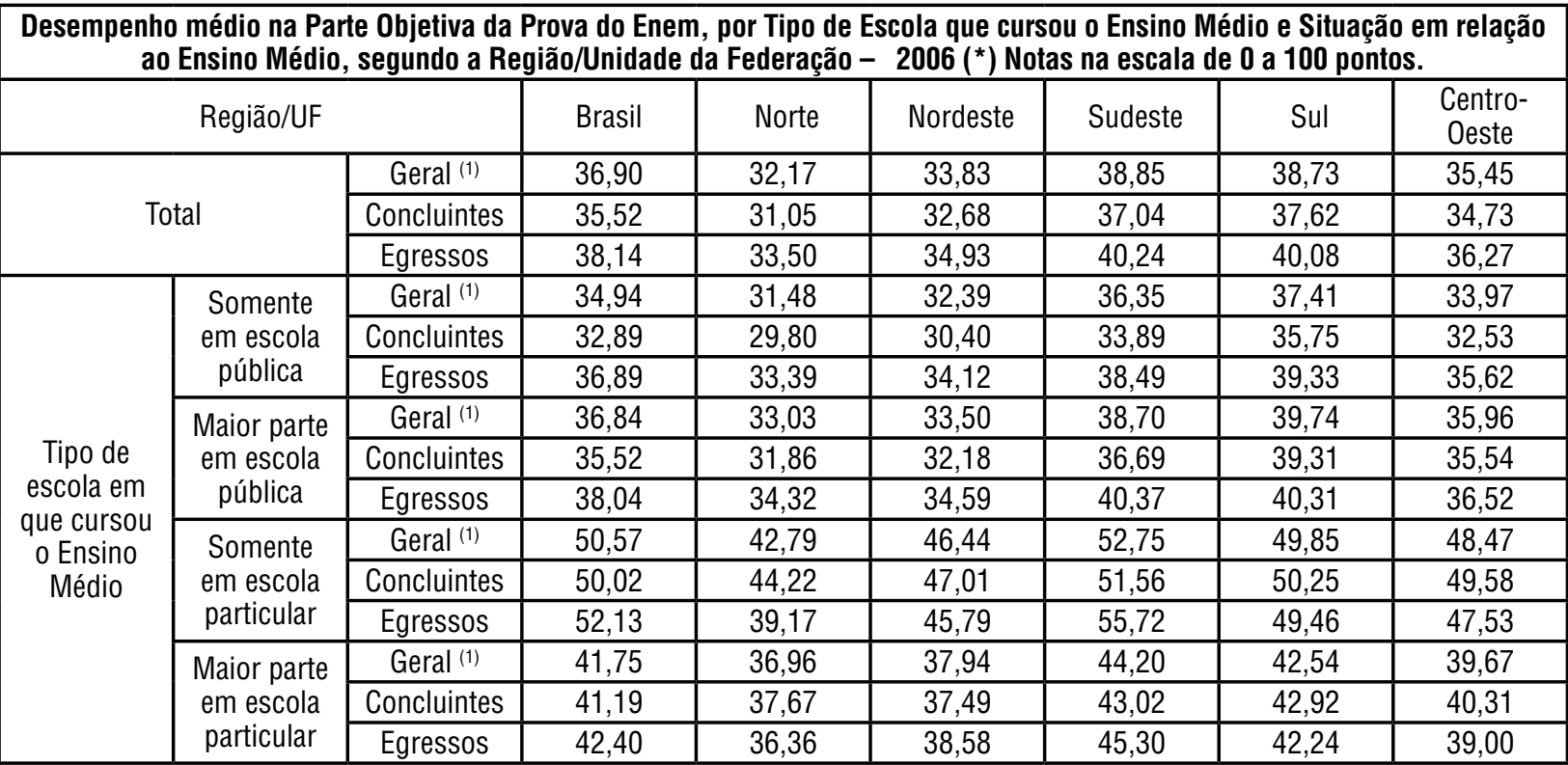

Nota: (1) Considera todos os participantes independente da situação em relação ao Ensino Médio. ${ }^{\star}$ ) Notas na escala de 0 a 100 pontos. Observação: Os participantes são candidatos do ENEM 2006 que fizeram a parte Objetiva da Prova.

Fonte: INEP (2006)

${ }^{2} O$ Programa de Avaliação Seriada é uma parceria entre a Secretaria e a USP. Foi criado após a avaliação favorável dos resultados iniciais do Programa de Inclusão Social da USP (Inclusp), que depois de dois anos de iniciado atingiu a meta de aumento no ingresso à USP de estudantes provenientes do ensino médio público. As notas no PASUSP poderão ser utilizadas no vestibular Fuvest 2009. Além da possibilidade de $3 \%$ de bônus adicional pelo Programa de Avaliação Seriada da Universidade de São Paulo, o indicador poderá contribuir para a avaliação do rendimento dos alunos do sistema de ensino estadual de São Paulo. (Site da SEE SP - 08.2008) 
E ainda, em relação ao desempenho na

avaliação baseada na redação:

Tabela 7. Desempenho médio no ENEM - Redação

\begin{tabular}{|c|c|c|c|c|c|c|c|c|}
\hline \multicolumn{3}{|c|}{ Região/UF } & Brasil & Norte & Nordeste & Sudeste & Sul & $\begin{array}{c}\text { Centro- } \\
\text { Oeste }\end{array}$ \\
\hline \multirow{3}{*}{\multicolumn{2}{|c|}{ Total }} & Geral $^{(1)}$ & 52,08 & 49,05 & 50,92 & 52,44 & 55,29 & 50,96 \\
\hline & & Concluintes & 50,72 & 46,85 & 48,80 & 51,19 & 54,61 & 49,98 \\
\hline & & Egressos & 53,40 & 51,70 & 52,83 & 53,47 & 56,16 & 52,11 \\
\hline \multirow{12}{*}{$\begin{array}{l}\text { Tipo de } \\
\text { escola em } \\
\text { que cursou } \\
\text { o Ensino } \\
\text { Médio }\end{array}$} & \multirow{3}{*}{$\begin{array}{c}\text { Somente } \\
\text { em escola } \\
\text { pública }\end{array}$} & Geral (1) & 51,23 & 48,65 & 50,16 & 51,52 & 54,72 & 50,04 \\
\hline & & Concluintes & 49,28 & 45,88 & 47,33 & 49,69 & 53,67 & 48,54 \\
\hline & & Egressos & 53,12 & 51,85 & 52,56 & 53,16 & 55,98 & 51,84 \\
\hline & \multirow{3}{*}{$\begin{array}{l}\text { Maior parte } \\
\text { em escola } \\
\text { pública }\end{array}$} & Geral (1) & 51,16 & 49,54 & 49,87 & 51,27 & 54,86 & 50,63 \\
\hline & & Concluintes & 50,18 & 47,03 & 47,70 & 50,45 & 55,13 & 50,48 \\
\hline & & Egressos & 52,15 & 51,91 & 51,62 & 52,04 & 54,86 & 51,06 \\
\hline & \multirow{3}{*}{$\begin{array}{c}\text { Somente } \\
\text { em escola } \\
\text { particular }\end{array}$} & Geral $^{(1)}$ & 59,77 & 58,00 & 59,49 & 59,88 & 60,59 & 59,55 \\
\hline & & Concluintes & 60,02 & 58,65 & 59,86 & 59,97 & 60,96 & 60,39 \\
\hline & & Egressos & 59,50 & 56,64 & 58,99 & 59,93 & 59,94 & 58,10 \\
\hline & \multirow{3}{*}{$\begin{array}{l}\text { Maior parte } \\
\text { em escola } \\
\text { particular }\end{array}$} & Geral (1) & 55,27 & 54,33 & 54,88 & 55,36 & 56,67 & 54,77 \\
\hline & & Concluintes & 55,52 & 54,21 & 54,79 & 55,50 & 57,83 & 55,56 \\
\hline & & Egressos & 55,11 & 54,80 & 55,09 & 55,20 & 55,47 & 54,26 \\
\hline
\end{tabular}

Nota: (1) Considera todos os participantes independente da situação em relação ao Ensino Médio. ( ${ }^{*}$ ) Notas na escala de 0 a 100 pontos.

Observação: Os participantes são candidatos do ENEM 2006 que fizeram a parte Objetiva da Prova.

Fonte: INEP (2006)

Numa análise abreviada, notamos que os alunos que concluem o ensino médio não demonstram o domínio satisfatório dos conteúdos elementares da escola básica, de competências fundamentais para o prosseguimento exitoso dos estudos e nem tampouco a fluência na escrita e produção de texto. Embora o fato seja mais agravante nos egressos da rede pública, o cenário não é tão diferenciado para aqueles que provêm da rede privada.

Em que pese a edição da lei 9394/96, que no seu título IV, capítulo IV dispôs sobre a educação superior no país, prevendo as finalidades cultural, científica e social desta etapa (artigo 43), a flexibilidade e diversificação dos cursos (artigo 44), a autonomia organizacional e as atribuições das universidades (artigos 52 e 53), não poderíamos ter a expectativa de que o descaso com o acesso e permanência nas escolas de ensino superior pudesse ser superado de imediato, por implicação legal.

Pelos apontamentos realizados pelo INEP e sistematizados por Moura Castro (2006) é justamente a ampliação da pirâmide de acesso e conclusão da escola básica que fortalece o ingresso no ensino superior, situação esta que requer historicamente um equacionamento no processo de atendimento à demanda e melhoria nos padrões de qualidade:

Tabela 8. Evolução das matrículas por nível de ensino (em mil)

\begin{tabular}{|c|c|c|c|c|}
\hline Nível & 1970 & 1985 & 1998 & 2004 \\
\hline Fundamental & 15.895 & 24.770 & 35.793 & 34.012 \\
\hline Médio & 1.119 & 3.016 & 6.969 & 9.169 \\
\hline Superior & 425 & 1.368 & 2.126 & 4.164 \\
\hline \multicolumn{5}{|c}{ Fonte: Castro, 2007. }
\end{tabular}

Ainda neste sentido, registramos que 19\% dos alunos matriculados em cursos superiores no país têm entre 25 e 29 anos, ou seja, fazem parte do grupo etário que foi, em algum momento de sua vida, excluído da progressão dos estudos e hoje retoma o percurso. Este dado é incrementado, quando constatamos que 38\% da população acadêmica no Brasil, está acima dos 25 anos de idade.

Alternativas de caráter organizativo e metodológico como a educação à distância ${ }^{3}$, prevista pelo artigo 80 da Lei 9394/96, contribuíram significativamente para a aceleração da entrada destes alunos no ensino superior nos últimos anos da década. Levantamento realizado pela Revista Ensino Superior, publicado em sua edição de maio de 2008, revela que mais de $10 \%$ de nossos alunos, que nas últimas décadas se 
dedicavam às modalidades mais formais de cursos, ingressaram em formas mais novas de oferecimento. Os cursos à distância, por exemplo, tiveram um aumento de cerca de 315\% em suas matrículas, fenômeno que também se apresenta no caso dos cursos de tecnólogos. Vejamos:

Tabela 9: Alunos do Ensino Superior por modalidade de Ensino - 2007

\begin{tabular}{|c|c|}
\hline Modalidade & Alunos \\
\hline Presencial & 4.676 .646 \\
\hline A Distância & 207.206 \\
\hline Tecnólogos & 287.727 \\
\hline
\end{tabular}

Fonte: Revista Ensino Superior, ano 10, n. 115, 2007.

Embora a expansão quantitativa seja um elemento determinante na democratização do ensino superior, alguns fatos como os apresentados por Martins (2000), ao constatar que nos anos 1990 as matrículas cresciam cerca de $54 \%$ nos anos finais do decênio, enquanto que as taxas de conclusão chegavam apenas aos $21 \%$, efeito direto da evasão sobre grande parte dos alunos ingressantes na educação superior. Segundo os dados do INEP, de 2007, os índices de não conclusão permanecem em torno dos $21 \%$, ou seja, não houve uma melhoria representativa nos mecanismos que pudessem reduzir a evasão.

De acordo com os estudos do INEP, por volta de $50 \%$ dos jovens com idade entre 18 e 24 anos de famílias com renda familiar superior a cinco salários mínimos, estão no ensino superior, enquanto que os estudantes oriundos do extrato de famílias com até três salários mínimos ficam abaixo de $12 \%$, conforme matéria da Revista Ensino Superior. Como efeito da renda familiar, temos a redução da demanda da população potencialmente candidata ao custeio próprio do ensino superior.

Moura Castro (2006) assinala que a elitização do ensino superior privado é tão grande quanto a do setor público, onde $70 \%$ dos seus ingressantes são egressos da camada populacional dos 20\% economicamente privilegiados no país.

Mesmo com investimentos públicos em políticas afirmativas como o FIES ou o Programa Universidade para todos (ProUni), que abrangem cerca de 200 mil alunos, não temos garantido ao menos $26 \%$ da população universitária. Resumidamente, estamos distantes da meta estabelecida pelo Plano Nacional de Educação - Lei 10.172/05 que prevê que 30\% de jovens entre 18 e 24 anos devam estar na educação superior, fato confirmado pelo censo da educação superior realizado pelo INEP em 2006.

Objetivamente, a Revista Ensino Superior, a partir de um levantamento estatístico realizado com base no ano de 2007, publicou alguns fatos que têm constituído o perfil dos alunos das escolas superiores no país:

- 39,73\% dos alunos que ingressam no ensino superior têm mais de 25 anos;

- 53,6\% dos estudantes estudam em universidades;

- $55,7 \%$ dos estudantes do ensino superior são mulheres;

- 53,7\% dos universitários declaram trabalhar em tempo integral;

- $87 \%$ dos alunos das instituições públicas de ensino superior estão nas camadas sociais chamadas C, B ou A;

- $73 \%$ dos alunos do ensino superior têm família cuja renda não ultrapassa dez salários mínimos;

- $52,2 \%$ dos estudantes do Brasil concluem o curso no tempo esperado e regular;

- 18,5\% é a taxa de evasão na educação superior, em parâmetros nacionais. Nas instituições públicas a média é de 12,4\%,

\footnotetext{
${ }^{2}$ Segundo os dados do Ministério da Educação (2006), havia no Brasil, cento e vinte e sete ISE oferecendo cursos à distância. Destas, 05 oferecem cursos seqüenciais, 32 exclusivamente de lato sensu, e 90 oferecendo graduação à distância, ainda que em caráter experimental, regulamentados pelo Decreto Presidencial 5622 de 2005, e 6303 de 2007. Ainda assim, nos cursos presenciais, de acordo com a Portaria do Ministério da Educação 4069 de 2004, nos cursos presenciais podem ser oferecidas atividades à distância, até o limite de $20 \%$ da carga horária total do curso.
} 
enquanto que nas instituições privadas este número chega a $25,1 \%$;

- dos 3,5 milhões de alunos matriculados no ensino privado, ou seja, $8 \%$ têm financiamento reembolsável do curso e 30\% algum tipo de bolsa institucional; e

- cerca de 145 mil alunos estão matriculados em cursos superiores subsidiados pelo Programa Universidade Para Todos - ProUni.

Pelo conjunto de indicadores que constituem o perfil dos alunos que ingressam na educação superior no Brasil, podemos concluir que não estamos tão próximos de alcançar padrões de qualidade aceitáveis, nem tampouco a universalização da educação superior, ainda que em longo prazo, atuando apenas na perspectiva de ampliação de vagas. A conjuntura educacional brasileira carece, portanto, do desenvolvimento de políticas de valorização da escolaridade juvenil, dos resultados de desempenho na escola média, e de melhoria das condições socioeconômicas da população.

\section{Considerações finais}

Embora devamos reconhecer que existem avanços consideráveis no que se refere à educação superior no Brasil, não mais restrita a um estrato definidamente determinado para o acesso, e que os últimos anos têm sido marcados por intensos debates sobre o sentido e o significado das escolas superiores no sistema educacional brasileiro, articulando-a ao conjunto de resultados também provenientes da educação básica, o que temos ainda é um ritmo de passos largos, mas por vezes de caminhos tortuosos e descontínuos.
Os dados que foram apresentados neste trabalho, as pesquisas que aqui evocamos para dialogar e as reflexões as quais procuramos contribuir para que venham à tona, demonstram que a distância entre a educação superior que temos, e a que efetivamente necessitamos para que seja alcançado um padrão de qualidade considerável, a democratização do acesso, e o fortalecimento de sua função social, ainda estão relativamente distantes.

Ademais, a expansão do número que escolas de ensino superior demanda um grande esforço no sentido de se estabelecer padrões de funcionamento e investimento, de modo que permaneça assegurada a missão de pesquisa que deve ocorrer no ensino superior, resguardados os preceitos legais, o que implica, sem sombra de dúvidas, na construção de uma identidade pedagógica, administrativa e institucional.

Indicadores de desenvolvimento da educação têm grande importância na educação, principalmente quando refletem a eficácia de medidas implantadas, ou apontam para a necessidade de mudança de rumos no que se pratica.

Certamente os desafios que temos a enfrentar não são poucos, todavia já existem sinais que demonstram que avanços também foram conquistados, e que um melhor padrão de qualidade é algo a ser alcançado com políticas educacionais eficazes e contínuas, o que demonstra que também a educação superior, não está definitivamente dentro de uma escola de vidro. 


\section{Referências bibliográficas:}

ANASTASIOU, L. das G. C. Metodologia do ensino superior: da prática docente a uma possível teoria pedagógica. Curitiba: IBPEX, 1998.

; ALVES, L., P. (org). Processos de ensinagem na universidade. UNIVILLE, 2005, mimeo.

AZZI, S. Trabalho docente: autonomia didática e construção do saber pedagógico. In: Saberes pedagógicos e atividade docente. São Paulo: Cortez, 2002, p. 35-60.

BARNARDO, M. B. C. (org). Ensaios sobre a formação do professor e a política educacional. São Paulo: Editora UNESP, 1999.

BENITO, A.; CRUZ, A. (coord). Nuevas chaves para la docencia universitária - en el espacio europeo de educación superior. Madri: Narcea Ediciones, 2005.

BRASIL. Lei de Diretrizes e Bases da Educação Nacional. Brasília: Ministério da Educação, 1996.

CASTRO, C. de M. Educação brasileira: consertos e remendos. Rio de Janeiro: Rocco, 2007.

Educação no Brasil: Atrasos, Conquistas e Desafios. Capítulo 3. In: Brasil - O estado de uma nação 2006. Brasília: IPEA, 2006.

CASTRO, M. H. G. A melhoria dos indicadores educacionais. In: Educação para todos - avaliação da década. Brasília: INEP, 2000, p. 57-62.

CHARLOT, B. Da relação com o saber. Elementos para uma teoria. Porto Alegre: Artmed, 2000, p. 59-76.

KRASILCHIK, M. Docência no ensino superior: tendências e mudanças. Cadernos de Pedagogia Universitária. São Paulo: Pró-Reitoria de Graduação da USP - EDUSP, 2008.

INSTITUTO NACIONAL DE ESTUDOS E PESQUISAS EDUCACIONAIS. Levantamento estatístico sobre o Ensino Médio e Educação Superior. Brasília: Ministério da Educação, 2006.

MACEDO, R. S. Currículo: campo, conceito e pesquisa. São Paulo: Vozes, 2007.

MARTINS, C. B. O ensino superior brasileiro nos anos 90. In: Revista São Paulo em Perspectiva. São Paulo: 2000, mimeo.

MOREIRA, D. A. (org). Didática do ensino superior - tendências e técnicas. São Paulo: Pioneira, 1997.

NÓVOA, A. O passado e o presente dos professores. In: (org) Profissão professor. Porto: Porto Editora, 1999, p. 14-34.

PERRENOUD, P. A formação dos professores no século XXI. In: (org) As competências para ensinar no século XXI - a formação dos professores e o desafio da avaliação. Porto Alegre: Artmed, 2002, p. 11-34.

PIMENTA, S. G. Professor reflexivo: construindo uma crítica. In: (org) Professor reflexivo no Brasil - gênese e crítica de um conceito. São Paulo: Cortez, 2002, p. 17-51.

. ANASTASIOU, L. das G. C; CAVALLET, V. J. Docência do ensino superior: construindo caminhos. In: Formação de educadores - desafios e perspectivas. São Paulo, UNESP Editora, 2003.

POZO, J. I. Aprendizes e mestres - a nova cultura da aprendizagem. Porto Alegre: Artmed, 2002, p. 23-40.

REVISTA ENSINO SUPERIOR. O que os números revelam - o retrato do ensino superior. São Paulo: ano 10, n. 115, 2007.

SCHWARTZAN, S. Os desafios da educação no Brasil. Rio de Janeiro, Nova Fronteira, 2005.

UNIVERSIDADE DO VALE DO ITAJAÍ. Seleção e organização de estratégias. In: Cadernos de formação contínua - ProEn. Itajaí: v. 2, 2002, p. 71-104.

VEIGA, I. P. A. Técnicas de ensino, por que não? Campinas: Papirus, 1991.

WOLF, R. P. O ideal da universidade. São Paulo: Editora UNESP, 1993, p. 89-105. 